\title{
Artigo
}

\section{Conselho Tutelar, Psicopedagogia e Escola: uma perspectiva de integração}

Conselho Tutelar (Guardianship Council), Psychopedagogy and School: an integration perspective

\section{Introdução}

As concepções de infância e de adolescência sofreram grandes transformações ao longo do tempo através de transformações históricas e culturais. Ainda como decorrência dessas mudanças e descontinuidades, o reconhecimento de suas identidades como sujeitos de direito, sobretudo no que diz respeito à educação e a seus direitos fundamentais, são fatos relativamente recentes. Num passado não muito remoto, a condição de cidadão não era reconhecida às crianças e aos adolescentes pelas legislações pertinentes. As lutas democráticas no Brasil na década de setenta e a redemocratização do país nos anos oitenta deram início a um debate que culminou com a elaboração da Constituição Federal de 1988. Em seu bojo, aprovou-se o Estatuto da Criança e do Adolescente (ECA) Lei $n^{\circ} 8.069^{1}$ de 13 de julho de 1990, que instituiu o então denominado Conselho Tutelar. Diante dessa nova realidade, constatou-se a necessidade de estabelecer um diálogo interdisciplinar entre a instância de defesa dos direitos da criança e do adolescente, o conselho tutelar, e a área de educação escolar, segundo Ferreira ${ }^{2}$.

Com mais de duas décadas de vigência, o ECA trouxe uma mudança de paradigma estrutural, filosófico e jurídico que modificou radicalmente a forma de considerar a infância e adolescência. O Código de Menores (1934-1989)³, de caráter punitivo-repressivo e prisional, atendia apenas crianças e adolescentes em situação irregular, o que significou um motivo de insatisfação constante das organizações sociais que se preocupavam com uma formação para a cidadania do público infanto-juvenil. A sociedade liberal desejava mudanças na legislação anterior, que

\section{Maria das Graças Vasconcelos de Paiva', Igor Collyer Lima Calandrini², Rosiane Seixas Placido da Rosa ${ }^{3}$, Bruna Cardoso Gonçalves ${ }^{4}$}

\section{Resumo}

Esta pesquisa visa investigar, através de queixas ao conselho tutelar, se a escola fundamental denuncia a violação dos direitos e deveres da criança e do adolescente à educação e verificar a frequência de demandas de dificuldade de aprendizagem e indisciplina. Participaram 17 conselheiros, sendo 9 da Cidade e 8 do Estado do Rio de Janeiro. Para obter as informações, foram realizadas entrevistas com os conselheiros nos próprios conselhos onde trabalham. As queixas mais frequentes são violência $(40,41 \%)$, faltas $(12,77 \%)$ e drogas $(7,45 \%)$, confirmando o alinhamento da escola com a doutrina de proteção integral. Por sua vez, a escola não se compromete, recusando sua responsabilidade de mudança da realidade de vida das crianças e adolescentes, encaminhando para o conselho tutelar casos de indisciplina $(12,77 \%)$ e dificuldades de aprendizagem $(6,38 \%)$. Os resultados mostram que muitos encaminhamentos poderiam ter sido resolvidos na própria escola sem necessidade de transferir a responsabilidade do problema para o conselho tutelar. O impacto da doutrina de proteção integral sobre a escola teve um efeito apenas parcial. Entre esses três campos _ psicopedagogia, escola e conselho tutelar não há nem efetiva integração, nem trabalho coparticipativo

Palavras-chave: Atendimento Psicopedagógico; Conselho Tutelar; Direito à Educação

Área temática: Direitos Humanos e Justiça Linha de Extensão: Direitos Humanos
Professora Associada. UERJ. E-mail: gracapaiva@hotmail.com Bolsista de Extensão. UERJ. E-mail: collyer_magister@hotmail.com 33olsista de Extensão. UERJ. E-mail: rosianespr@gmail.com ${ }^{4}$ Aluna do curso de Especialização. UERJ.E-mail: brunacardosog@hotmail.com 
começou a se desconstruir dando lugar ao ECA. $\mathrm{Na}$ conquista da nova legislação, tiveram relevância documentos internacionais que apoiaram a luta das forças democráticas nacionais. Nesse processo, é ressaltada a Declaração dos Princípios de Direitos da Criança das Organizações das Nações Unidas (ONU) (1959)4. O Brasil, país signatário dessa declaração, se comprometeu em assinar e cumprir os preceitos aí previstos. Em 1989, a Convenção da ONU expandiu os princípios dos direitos da criança e do adolescente, propondo mudanças fundamentais. Corroborando com Souza, Teixeira e Silva ${ }^{5}$, que se referem como sendo a mais significativa coparticipação dos recursos para jovens e crianças conquistarem seus direitos através da participação da família, do estado, da comunidade e de ações sociais. As propostas de coparticipação coincidiam com aquelas que determinavam a proposta constituinte, ou seja, adotar a democracia participativa.

O conselho tutelar tem como finalidade assegurar a aplicação da Lei n. $8.069($ art. 131)1 e providenciar medidas de proteção sempre que os diretos na Lei forem ameaçados ou violados. Trata-se de um órgão municipal, encarregado pela sociedade de zelar pelo cumprimento dos direitos da criança e do adolescente (ECA, art.131) ${ }^{1}$. Ele inovou a forma de interação entre o poder público e a sociedade por representar uma aproximação do judiciário com a população. Segundo Konzen $^{6}$, o conselho tutelar é autônomo, isto é, independente para agir, e suas ações somente podem ser revogadas pelo Juiz da Infância e da Juventude e tem caráter permanente, ou seja, passou a integrar de forma definitiva o quadro das instituições públicas que desenvolvem uma ação contínua e ininterrupta na comunidade com relação à infância e adolescência. É não jurisdicional, pois não integra o poder judiciário, portanto não exerce atribuições típicas desse poder, como julgar, sancionar e sentenciar. Está estruturado no município e para lá devem ser encaminhadas, conforme o ECA, as situações de violação dos direitos e não cumprimento dos deveres de crianças e de adolescentes.

A atividade do agente tutelar, por situarse na esfera administrativa da Justiça, limita-se a verificar a situação, formar seu juízo de valor e determinar, a partir de seu julgamento, a melhor providência para o caso concreto. $\mathrm{O}$ agente tutelar é o ponto intermediário entre o juiz e a comunidade.

No ECA, cap.IV ${ }^{1}$, a educação está descrita como um direito de todos e dever do Estado e da família, promovida com a colaboração da sociedade. O ECA traçou os seguintes objetivos a serem atingidos com respeito à educação: buscar o desenvolvimento pleno da criança e do adolescente; preparar para exercer a cidadania e qualificar para o trabalho. No seu artigo $56^{1}$, estabeleceu as obrigações impostas aos diretores das instituições escolares: comunicar ao conselho tutelar os casos de maus tratos de alunos, faltas dos alunos reiteradas e sem justificativas, evasão escolar e repetência elevada.

O conselho tutelar, no exercício de suas atribuições já descritas, estabeleceu em 2010 um relacionamento profícuo com o Serviço de Psicologia Aplicada (SPA) da Universidade do Estado do Rio de Janeiro (UERJ). O setor que recebia os casos dos conselhos tutelares era o de Psicopedagogia, através do projeto de extensão "Psicopedagogia Terapêutica" com sua equipe e um estagiário bolsista de extensão. Chegavam ao SPA solicitações de diversos conselhos tutelares da Cidade do Rio de Janeiro e da sua periferia. Estas se referiam a crianças e adolescentes que apresentavam dificuldades de leitura ou que ainda não tinham aprendido a ler. Nos encaminhamentos, nem sempre havia os dados necessários de identificação do interessado relativos a endereços para contato com as famílias, com as escolas onde as crianças e adolescentes estavam matriculados ou com o conselho tutelar, o que dificultava muito o atendimento.

Quanto às solicitações dos conselheiros dois questionamentos foram considerados pela equipe de atendimento: por que só surgiam como queixas, embora devidamente explicitadas, as dificuldades de leitura? Por que faltavam sempre os dados de identificação necessários para um contato imediato com a família da criança ou do adolescente?

Depois de um ano de trabalho, estávamos motivados a nos aproximar dos conselhos tutelares para investigar, no conjunto das queixas da escola, as denúncias de violação dos direitos e deveres da criança e do adolescente e investigar a frequência de demandas que acarretavam dificuldades de aprendizagem e justificavam intervenção psicopedagógica a fim de realizar um trabalho de cunho interdisciplinar com o conselho tutelar. 


\section{Psicopedagogia e Escola: parceria para o ensino de qualidade.}

Crianças com capacidade de desempenho intelectual satisfatório repetem o ano, evadem ou terminam a escola sem dominar a leitura e a escrita. A maioria é derrotada por carências sociais e não cognitivas. Muitas que pertencem a esse quadro são encaminhadas pela escola ao conselho tutelar por indisciplina ou dificuldades de aprendizagem. Esse dado confirma um entendimento errôneo de que o baixo rendimento nas escolas públicas se deve ao baixo nível socioeconômico da população. Outros fatores devem ser considerados para explicar o baixo rendimento (ambiente familiar impróprio, violência urbana, desadaptação escolar, nível de instrução dos pais, entre outros) que atinge os menos economicamente favorecidos. Contudo, há escolas cuja população é de nível socioeconômico abaixo da pobreza que provam o contrário. Receberam uma avaliação pelo IDEB (Índice de Desenvolvimento da Educação Básica) comparável a escolas que atendem crianças em situação socioeconômica não tão precária. Contudo, ocorre nessas escolas um esforço da direção e dos professores para não deixar que nenhum aluno fique para trás; verificam-se poucos casos de indisciplina e buscam corrigir as deficiências de aprendizagem e cuidam da frequência, procurando pelo aluno logo após faltas repetidas de acordo com a reportagem ${ }^{7}$. A psicopedagogia é uma proposta interdisciplinar que busca compreender os comportamentos e problemas cognitivos e emocionais da criança em situação de fracasso ou baixo desempenho escolar. Não se limita apenas à consideração de questões pedagógicas, pois se trata de uma área do conhecimento que reflete sobre as relações entre quem aprende e o objeto de sua aprendizagem em diferentes perspectivas. Essa interdisciplinaridade, essa soma de forças de distintos profissionais em sinergia, é fator preponderante para a solução problemas gerais ou pontuais.

Numa abordagem psicopedagógica, o profissional não classifica quem aprende e quem não aprende, mas trabalha os processos psicológicos e subjetivos do ato de aprender, a motivação consciente e até os processos inconscientes que bloqueiam o prazer de aprender ${ }^{8}$. Seu objeto de estudo são as dificuldades de aprendizagem, con- ceito que, apesar dos esforços científicos, não têm ainda uma definição universal.

Um indivíduo com dificuldades de aprendizagem pode apresentar as seguintes características: capacidade intelectual e ausência de problemas sensoriais ou motores, adequada oportunidade instrucional e adaptação emocional. Até mesmo indivíduos com alto coeficiente intelectual e de meio socioeconômico privilegiado podem apresentar dificuldades de aprendizagem. É uma variável muito sensível ao fator desenvolvimento e dificilmente pode ser diagnosticada antes do fim da pré-escola ou no início do ensino fundamental. Todo professor procura saber que força estranha pode impedir crianças inteligentes e curiosas de colocar em ação os meios de que dispõem para adquirir a aprendizagem escolar. Além de uma contestação do sistema e dos métodos escolares, a própria situação de aprendizagem escolar, por seu caráter sistemático, provoca medos que perturbam a organização intelectual. São inerentes à situação de aprendizagem escolar inquietudes e medos contra os quais algumas crianças e alguns adolescentes não podem lutar apenas com as ferramentas pedagógicas ordinárias que lhes são oferecidas, segundo Boimare" confrontação com a regra e com a autoridade; o encontro com a falta, a tolerância, a dúvida e a solidão. A psicopedagogia pode ajudar a criança e o adolescente a elaborar os medos, ajudandolhes a dar uma forma suportável ao pensamento. Através da elaboração, essas ameaças subjetivas não provocam a ruptura do desenvolvimento intelectual. A psicopedagogia utiliza também uma metodologia específica, denominada clínica, que a torna uma condição indispensável para reconciliar o sujeito com a aprendizagem escolar.

É pertinente a preocupação de alguns autores quanto a um eventual desvio de suas funções por parte do conselho tutelar. Nascimento e Scheinvar ${ }^{10}$ apontam para o risco do conselho tutelar envolver-se em atividades práticas tipicamente jurisdicionais. Colocam a seguinte pergunta: como um órgão proposto para ser não jurisdicional pode chegar a ocupar tal função disciplinar e punitiva no mundo subjetivo das crianças? Caso isso venha a acontecer, o conselho tutelar estaria exercendo um papel normativo e controlador, desvirtuando-se, portanto, de sua função de origem. Entre as atividades exer- 
cidas pelo psicopedagogo, Bossa ${ }^{11}$ acrescenta a orientação de estudos, a apropriação dos conteúdos escolares, o desenvolvimento do raciocínio, o atendimento de crianças, a intervenção e a pesquisa. A intervenção psicopedagógica apresenta a vantagem de permitir que crianças e adolescentes com atraso escolar sejam autores de sua aprendizagem; que aprendam a pensar e possam adquirir conhecimentos que os ajudem na aprendizagem. Para as crianças e adolescentes carentes, aprender não é tarefa simples nem evidente, pode consistir num questionamento, pelo menos em parte, de uma maneira de ser. A intervenção psicopedagógica pode fornecer a essas crianças os meios de lutar contra as forças que as obrigam a restringir seu pensamento. Alguns podem se sentir desestabilizados quando enfrentam problemas de aprendizagem escolar devido a um equilíbrio emocional precário. De fato, eles possuem uma organização pessoal, um modo de funcionamento psíquico muitas vezes incompatível com os diferentes caminhos que levam à aprendizagem escolar. Segundo Boimare', a maioria dessas crianças e adolescentes suportou desde os primeiros meses de vida a incoerência, exigências excessivas, carências, a violência do meio familiar e urbano sem se desunir, sem sofrer demais, sem perder contato com a realidade. O caminho do saber é difícil e doloroso porque desestabiliza uma organização frágil, que se mantém evitando a frustração e a tensão.

\section{Objetivos}

Investigar, no conjunto das queixas da escola ao conselho tutelar, a denúncia de violação dos direitos e deveres educacionais para cumprir as prerrogativas do ECA. Compreender, a partir das queixas da escola ao conselho tutelar, a frequência com que ocorrem queixas de dificuldades de aprendizagem e de indisciplina ao conselho tutelar.

\section{Proposições}

- A escola faz demandas ao conselho tutelar quando os direitos e deveres à educação da criança e do adolescente estão sendo violados

- O atendimento psicopedagógico às dificuldades de aprendizagem e indisciplina são atribuições da escola.

\section{Método}

\section{Participantes}

Participaram 17 conselheiros pertencentes a 17 conselhos tutelares. Em cada conselho foi agendada a entrevista com um ou mais conselheiros. No interior do Estado do Rio de Janeiro foram entrevistados oito conselheiros. Na cidade do Rio de Janeiro, foram entrevistados nove conselheiros, situados nas zonas norte, sul, oeste e periferia (ver tabela 1).

\section{Instrumento}

$\mathrm{O}$ instrumento utilizado foi uma entrevista semidirigida, com perguntas abertas relacionadas às demandas que a escola faz ao conselho tutelar. Exemplo: Como os professores reagem à indisciplina? Eles denunciam casos de maus tratos quando detectados? Quais os principais desafios que enfrentam os professores na escola atualmente?

Também foram feitas perguntas fechadas para conhecer a estrutura, a rotina e a divisão do trabalho nos conselhos tutelares visitados.

\section{Procedimento}

A coleta de dados (duração 2010-2011) iniciou-se com o contato telefônico pelo bolsista de extensão com o conselho tutelar e o agendamento de uma entrevista com um conselheiro. A entrevista foi realizada individualmente e no próprio conselho tutelar onde o conselheiro trabalhava. No primeiro contato, era exposto o objetivo da pesquisa, agendada a entrevista e destacado o sigilo das informações ali fornecidas, assegurando-lhes que seriam tomados todos os cuidados éticos necessários, bem como garantindo-lhes o anonimato de sua identificação. $\mathrm{O}$ entrevistado deu a sua cooperação espontânea e a entrevista teve início depois que este assinou o Termo de Consentimento Livre e Esclarecido. As perguntas eram feitas oralmente e registradas em uma folha de papel pelo entrevistador. O tempo para a entrevista livre foi de 50 a 55 minutos. Finalizavase, agradecendo pelo apoio e colaboração.

\section{Resultados}

Pela análise dos resultados, os conselhos tutelares são mais procurados por indivíduos da classe popular. O Gráfico 1 mostra a distribuição amostral do total de 94 ocorrências referentes à questão "quem procura ou não procura" o conselho tutelar. 


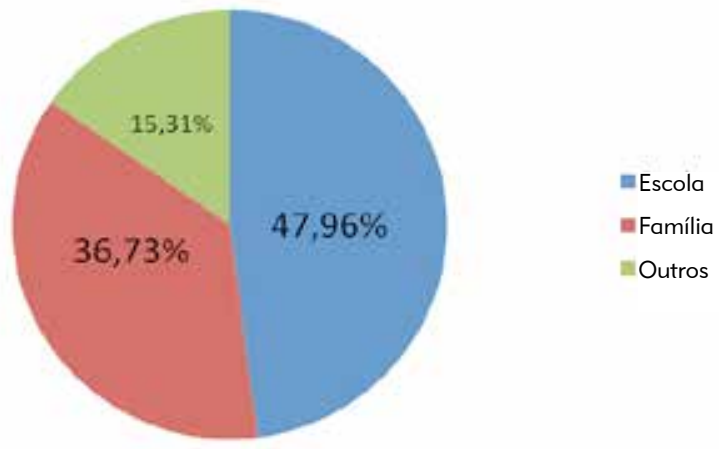

Gráfico 1 - Distribuição do percentual das queixas da população: escola, família e outros
Segundo os resultados, a maior parte das ocorrências é da escola $(47,96 \%)$, e serão aqui analisadas. A procura pela família é considerável $(36,73 \%)$. O conselho tutelar ainda recebe queixas oriundas de delegacias, hospitais, Disque 100, Disque-denuncia e de pessoas que não desejam se identificar, $(15,31 \%)$, que foram categorizados como "outros".

Tabela 1: Características da amostra

\begin{tabular}{|c|c|c|c|c|c|c|}
\hline Entrevistas & $\begin{array}{c}\mathrm{N}^{\circ} \text { de } \\
\text { Componentes }\end{array}$ & $\begin{array}{l}\text { Equipe } \\
\text { Técnica }\end{array}$ & Localização & Reconduzido & $\begin{array}{c}\text { Curso de } \\
\text { Atualização }\end{array}$ & Reunião \\
\hline 1 & 5 & 0 & I. Grande & NÃO & NÃO & Ocasional \\
\hline 2 & 5 & IAS & C. Macacu & NÃO & SIM & Sem dados \\
\hline 3 & 5 & 0 & A. do Cabo & NÃO & SIM & Quinzenal \\
\hline 4 & 5 & IAS; IPS & Cabo Frio & NÃO & NÃO & Semanal \\
\hline 5 & 5 & $1 \mathrm{AS} ; 1 \mathrm{PS}$ & São Gonçalo & NÃO & NÃO & Quinzenal \\
\hline 6 & 5 & 3AS; $1 P S$ & Centro - RJ & NÃO & SIM & Mensal \\
\hline 7 & 5 & 3AS; 1PS & Laranjeiras & NÃO & SIM & Semanal \\
\hline 8 & 5 & 2AS; $1 P S$ & Bangu & SIM & SIM & Mensal \\
\hline 9 & 5 & IAS; IPS; 1A & Tanguá & NÃO & NÃO & Mensal \\
\hline 10 & 5 & 3AS; 1 PS & Vila Isabel & NÃO & SIM & Semanal \\
\hline 11 & 5 & 3AS; 1 PS & Madureira & SIM & SIM & Semanal \\
\hline 12 & 5 & 3AS; 1PS & Santa Cruz & SIM & SIM & Semanal \\
\hline 13 & 5 & $1 \mathrm{AS} ; 1 \mathrm{PS}$ & Eng. Dentro & NÃO & NÃO & Sem dados \\
\hline 14 & 5 & 3AS; 1PS & Jacarepaguá & NÃO & SIM & Semanal \\
\hline 15 & 5 & 3AS; 1PS & RJ - Ramos & SIM & SIM & Semanal \\
\hline 16 & 5 & IPS & Nova Iguaçu & SIM & SIM & Semanal \\
\hline 17 & 5 & IAS; IPS & B. Roxo & NÃO & SIM & Mensal \\
\hline TOTAL & & $\begin{array}{c}\text { 29AS, 14PS, } \\
\text { IAD }\end{array}$ & & $\begin{array}{l}29,41 \%(\operatorname{Sim}) \\
70,58 \% \\
\text { (Não) }\end{array}$ & $\begin{array}{l}70,58 \% \text { (Sim) } \\
29,41 \% \text { (Não) }\end{array}$ & \\
\hline
\end{tabular}

Legenda: AS - Assistente Social; PS - Psicólogo; A - Advogado

\section{Contexto de trabalho: Atendimento e interdisciplinaridade e atualização}

Atendimento - Uma política de atendimento à criança e ao adolescente deve ser abrangente e eficaz, exige infraestrutura e verbas para a solução de problemas básicos de saúde e educação. O conselho tutelar é uma instituição que carece de recursos materiais e humanos para o funcionamento.
Interdisciplinaridade - Conforme a Tabela 1, um alto percentual de conselhos tutelares $(88,23 \%)$ possui equipes técnicas incompletas formadas por assistentes sociais e psicólogos. A psicopedagogia não se encontra representada através de seus profissionais em nenhuma equipe técnica. Constatou-se nas entrevistas que não há uma integração entre a equipe técnica e a equipe de conselheiros nem relato de reuniões entre as 
equipes. A experiência interprofissional é fundamental nos nossos dias para potencializar o trabalho. As equipes não têm uma prática coletiva, trabalham de forma independente, indicando um não reconhecimento da interdisciplinaridade entre psicologia, psicopedagogia e conselho tutelar (Tabela1).

Atualização - Durante o período de atuação são oferecidos cursos de atualização aos membros dos conselhos tutelares. Boa parte os realizou (70,58\%), mas apesar da oferta constante de bons cursos, eles não têm tempo para realizá-los. $\mathrm{Na}$ amostra estudada, 29,41\% são reconduzidos ( $\mathrm{Ta}$ bela 1).

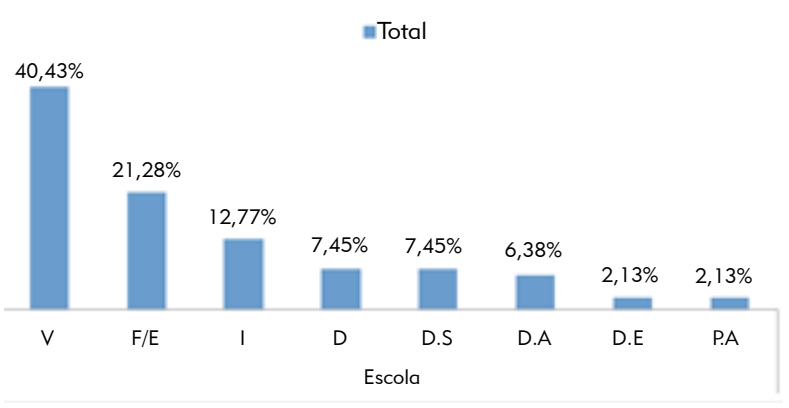

Gráfico 2 - Percentual de queixas no campo da escola. Em que: $V$ - Violência; F/E - Faltas e

Evasão-evasão. I - Indisciplina; D - Drogas; D.S Direitos sociais; D.A - Dif. de Aprendizagem e D.E - Dist. Emocional e P.A - Pedido de Atendimento

O gráfico 2 mostra as principais queixas encontradas na análise das entrevistas. As principais demandas da escola são: problemas de: violência $(40,43 \%)$, faltas $(21,28 \%)$, indisciplina $(12,77 \%)$, drogas $(7,43 \%)$, diretos sociais (7,45\%), dificuldade de aprendizagem (6,38\%), distúrbio emocional $(2,13 \%)$ e pedido de atendimento $(2,13 \%)$. Na categoria droga, foram encontrados alcoolismo dos pais, o uso de bebida alcoólica e de crack por escolares e roubos para comprar a droga. "Direitos sociais" nomeiam questões que podem impedir a frequência à escola e levar à evasão de muitos alunos. Neles incluem-se a deficiência de transporte, o trabalho infantil e a gravidez na adolescência. As crianças com dificuldade de aprendizagem e indisciplina demandam atendimento psicopedagógico na escola. "Pedido de atendimento" denomina as solicitações de internação hospitalar, de matricula escolar em creche e pedido de transferência, entre outros.

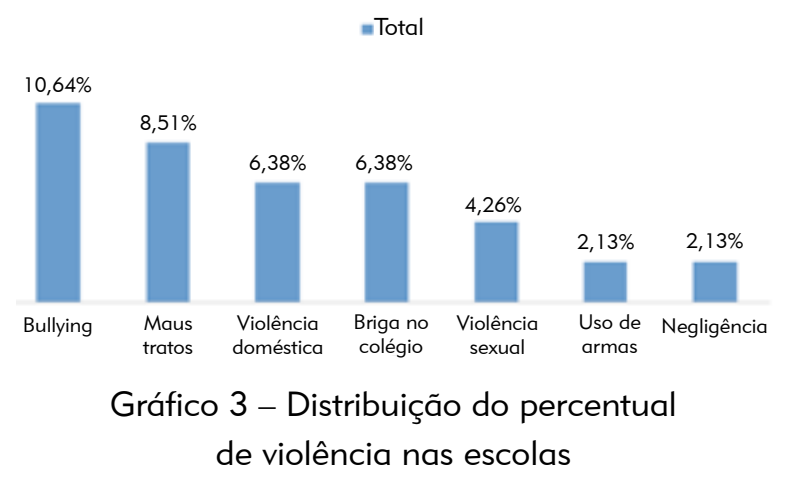

O gráfico 3 mostra a distribuição percentual das queixas de violência contra a criança. Este fator causa, entre outros problemas, dificuldade de aprendizagem, agressividade e depressão. A análise dos dados indica que há uma maior ocorrência de bullying (10,64\%), tipo de abuso psicológico que consiste em toda forma de rejeição, depreciação, discriminação, desrespeito, cobranças exageradas e punições humilhantes. Em seguida, aparecem maus tratos $(8,51 \%)$, que incluem a violência física ainda muito praticada em nosso meio. $\mathrm{O}$ ambiente escolar parece reproduzir a violência que reina na família em igual proporção $(6,38 \%)$. O percentual de violência sexual $(4,26 \%)$ pode não corresponder à verdade dos fatos, pois se sabe que entre todos os tipos de violência, é a ligada ao sexo a mais dificilmente denunciada, dando a falsa impressão de que não ocorre. $O$ percentual de uso de arma de fogo, apesar de baixa, não deixa de ser muito preocupante devido às graves consequências que pode provocar. O termo negligência $(2,13 \%)$ é internacionalmente adotado para se nomearem as omissões dos pais ou dos responsáveis pela criança ou adolescente, quando esses adultos deixam de prover as necessidades básicas para seu desenvolvimento físico, emocional e social. Crianças e adolescentes que convivem com a violência doméstica $(6,38 \%)$ podem apresentar rendimento escolar baixo e outras incapacidades, sentimentos impróprios, humor depressivo, tendência a desenvolver problemas psicossomáticos. Pode surgir ocorrência da vitimização nos ambientes escolares, comportamento de infração das normas e problemas emocionais ligados ao estresse e comportamento violento em relação a outros na escola. 


\section{Considerações Finais}

O fato de haver maior proporção de crianças e adolescentes enviadas vítimas ou autoras de violência $(40,42 \%)$ reforça a proposição de que, através das demandas da escola, o conselho tutelar recebe denúncias de direitos infanto-juvenis violados. Os resultados ilustram a presença de diferentes tipos de violência contra a criança e o adolescente, que gradativamente deixam de permanecer encobertos e começam a ser denunciados. Com o objetivo de combater o absenteísmo escolar, elaborou-se a ficha individual de controle do aluno infrequente (FICAI), considerada efetiva pelos conselheiros por facilitar a fiscalização e intensificar o contato com a escola e com as famílias das crianças infrequentes. Fiscalizar somente não basta, no entanto. É necessário compreender o mundo subjetivo do sujeito para conhecer como ele reage às influências e conflitos gerados pelo meio e pela interferências entre eles, para questionar e dimensionar o processo de absenteísmo da escola primária e, sobretudo, do ensino médio. Com relação às queixas de dificuldades de aprendizagem e disciplina, que juntas perfazem 13,83\%, os conselheiros, sem discordância, consideram que são de competência da escola. Para eles, esse fato é sinal de que a escola ainda não está em condições de ser inclusiva e de atender seus alunos fornecendo uma educação de qualidade. $\mathrm{O}$ aluno não teria incentivo porque as aulas têm conteúdo pouco interessante e a escola conta com instalações precárias e professores que não têm salários dignos, o que prejudica a relação professor $\mathrm{x}$ aluno. Os conselheiros se declararam insatisfeitos porque a escola transfere para o conselho tutelar um caráter jurisdicional, de punição e normatização do cotidiano escolar que não é característico do órgão, o que demonstra mau uso ou ignorância da função fundamental do conselho tutelar. Conclui-se que as três instâncias (psicopedagogia, escola e conselho tutelar), apesar de buscarem os mesmos objetivos (defesa dos direitos da criança à aprendizagem, combate ao atraso escolar e cidadania) não se interagem numa ação coparticipativa.

Agradecimentos à UERJ e à Sub-Reitoria de Extensão (DEPEXT) pelas bolsas de extensão concedidas aos alunos Igor Collyer Lima Calandrini e Rosiane Seixas Plácido da Rosa.

\section{Referências}

1. BRASIL. Ministério da Saúde. Estatuto da Criança e do Adolescente. 2. ed. Brasília (DF): Ministério da Saúde, Série E. Legislação de saúde, 2003. 114 p.

2. FERREIRA, L. A. M. O Estatuto da Criança e do Adolescente e o Professor: reflexos na sua formação e atuação. 2. ed. - São Paulo: Cortez, 2010. 143 p.

3. BRASIL. Código de Menores (1927). Código de Menores: Decreto n. 17.943-A, de 12 de outubro de outubro de 1979 e legislação posterior. Rio de Janeiro: In: BRASIL. Ministério da Saúde. Violência Faz Mal a Saúde. 1. ed. Brasília p. 298. 2006.

4. ONU. Declarations of the rights of the child. United Nations General Assembly Resolution 1386 (XIV) of 20 November 1959. Disponível em: <http://www.un.org/documents/ga/res/14/ares14.htm>. Acesso em: 8 dez. 2013.

5. SOUZA, M. P. R.; TEIXEIRA, D.C. da S.; GONÇALVES da SILVA, M. C. Y. Conselho Tutelar: um novo instrumento social contra o fracasso escolar. Psicologia em Estudo, Maringá, v. 8, n. 2, p. 71-82. 2003.

6. KONZEN, A. A. Conselho Tutelar, escola e família - parcerias em defesa do direito à educação. In: KONZEN, Afonso Armando (Org.) et al. Pela Justiça na Educação. Brasília: FUNDESCOLA/MEC, p. 159-191, p. 720. 2000.

7. GÓIS, A.; OTAVIO, C. O. Aula de excelência na pobreza. Reportagem. O GLOBO. Rio de Janeiro, p.3, 8 Jul. 2012.

8. MACEDO, L. Disciplina é um conteúdo como qualquer outro. Disponível em: <http://revistaescola.abril.com.br/crianca-e-adolescente/comportamento/disciplina-conteudo-como-qualquer-outro-431413.shtml>. Acesso em: 31 Ago. 2012.

9. BOIMARE, S. L'Énfant et la peur d'apprendre. Ed. Dunod, Paris, p. 196, 2004.

10. NASCIMENTO, M. L.; SCHEINVAR, E. De como as práticas do conselho tutelar vêm se tornando jurisdicionais. Disponível em: <http://www.redalyc.org/articulo. oa?id=115013454012>. Acesso em: 1 Jun. 2012.

11. BOSSA, A. N. Psicopedagogia no Brasil: Contribuições a partir da prática. $2^{\mathrm{a}}$ ed. Porto Alegre: ArtMed, p. 131, 2000. 


\section{Abstract}

This research aims to investigate, through complaints to the Tutelary Council, if school denounces the violation of fundamental rights and duties of the child and adolescent education and check the frequency demands of learning difficulties and discipline. Participants were 17 counselors, being 9 of the City of Rio de Janeiro and 8 of the State of Rio. Information was obtained through interviews with counselors in their own councils where they usually work. The more common complaints are violence $(40.41 \%)$, fouls $(12.77 \%)$ and drugs $(7.45 \%)$, confirming the alignment of the school with the doctrine of integral protection. In turn, the school does not engage itself in the problem, refusing their responsibility to change the reality of life for children and adolescents, and not sending to the Tutelary Council discipline cases (12.77\%) and learning disabilities (6.38\%). The results show that many referrals could have been resolved at the school without the need to transfer responsibility for the problem of tutoring assistance. The impact of the doctrine of integral protection of the school had a partial effect. There is not a really integration between people representing the Tutelary Council, Psychopedagogy and Elementary School who wre suppose to perform a joint work.

Keywords: Psychopedagogy; Guardianship Council; Right to Education 